\title{
FREUD E A FILOSOFIA: INCIDÊNCIAS DE FRIEDRICH NIETZSCHE
}

\author{
FREUD AND PHILOSOPHY: THE IMPACT OF FRIEDRICH NIETZSCHE
}

\author{
Wellington Santos* \\ João Lucas Santos Ulhoa**
}

\section{RESUMO}

O presente artigo tem como objetivo uma investigação de possíveis atravessamentos da filosofia de Friedrich Nietzsche na psicanálise de Sigmund Freud. Esclarece, em primeiro lugar, a controversa relação de Freud com a filosofia de maneira geral, ressaltando uma postura inicial de entusiasmo por este campo do saber, depois de recusa e afastamento aparentemente intencional. Entende que este distanciamento é um posicionamento político por parte de Freud para evitar demasiadas influências externas na formulação de sua teoria. Depois, destaca as menções a Nietzsche encontradas ao longo da obra freudiana e, por fim, examina as incidências do filósofo que poderiam ser encontradas na psicanálise. Através desta análise percebe-se como Freud, apesar de declarar não conhecer a obra de Nietzsche, demonstra leitura e conhecimento dela. Conclui destacando que o conceito freudiano de inconsciente e o de Além-do-homem nietzschiano, aqui eleitos como conceitos-chave para pensar esses atravessamentos, marcam pontos privilegiados de convergência e divergência para ambos os autores.

PALAVRAS-CHAVE: Psicanálise. Filosofia. Consciente. Inconsciente. Além-do-homem.

\section{ABSTRACT}

The present article aims at an investigation of possible incidence of Friedrich Nietzsche's philosophy in Sigmund Freud's psychoanalysis. It clarifies, firstly, Freud's controversial relationship with philosophy in general, emphasizing an initial posture of enthusiasm for this field of knowledge, and then apparently an intentional refusal and withdrawal from it. It understands that Freud`s detachment is a political position on his part to avoid too many outside influences in the formulation of his theory. It then highlights the references to Nietzsche found throughout the Freudian work and, finally, examines the incidences of the philosopher that could be found in psychoanalysis. It concludes by pointing out that the Freudian concept of the unconscious and that of the Nietzschean Übermensch, here as key concepts for thinking about these intersections, mark privileged points of convergence and divergence for both authors.

KEYWORDS: Psychoanalysis, Philosophy. Conscious. Inconscious. Übermensch.

\footnotetext{
* Graudado em Filosofia e Teologia pela PUC Minas e Pós-graduando em Filosofia Contemporânea pela PUC Minas. E-mail: wellin.san@gmail.com.

** Graduado em Música, Bacharelado em flauta trasnversal pela UEMG e Graduando em Psicologia pela PUC Minas. E-mail: jlulhoa@gmail.com.
} 


\section{INTRODUÇÃO: A RELAÇÃO DE FREUD COM A FILOSOFIA}

Para inferirmos sobre a relação de Freud com a filosofia, destacando sua posição política frente a esta em dois momentos distintos, e as incidências de Nietzsche em seu sistema psicanalítico, vamos tomar como referência o texto do psicanalista francês PaulLaurent Assoun. Em sua pesquisa, ele garimpou a vida de Freud, especialmente sua juventude, para determinar os muitos momentos de aproximação do pai da psicanálise com a filosofia e os filósofos. Ao lermos a história da juventude de Freud, vamos encontrá-lo em constante contato com o discurso filosófico, estudando o pensamento de vários filósofos. Num outro momento, encontraremos um Freud que declarava total desconhecimento do pensamento especulativo, a filosofia. Assim ele se expressa ao pedido da professora francesa de filosofia, Favez-Boutonier, quando solicitado a expressar sua opinião sobre questões de ordem metafísica: "Os problemas filosóficos e suas formulações me são tão estranhos, que não sei o que dizer sobre eles, nem sobre a filosofia de Spinoza" (ASSOUN, 1978, p. 23). Antagonismos que revelam a posição política de Freud frente à filosofia; ora interessado pelos estudos filosóficos, ora completamente alheio à especulação.

Freud teve um contato mais direto e mais sistemático com a Filosofia a partir das conferências e cursos ministrados por Franz Brentano. Este filósofo e psicólogo alemão haveria de cativar a atenção de Freud para esse campo do saber, relevante na época, se não em toda a história do pensamento humano. Brentano veio a ser como que o guru do jovem Freud em sua iniciação no pensamento especulativo. Em Viena, polo da elite intelectual e lugar da gênese de muitos gênios, Freud, inscrito na Faculdade, passa a frequentar assiduamente as reuniões de leituras mantidas por Brentano, com o intuito de adquirir certas noções de filosofia.

\footnotetext{
Sigmund Freud, constata-se que ele foi particularmente assíduo a essas reuniões, institucionalmente facultativas, que se acrescentavam a um ensino científico já pesado. Tudo se passa como se Freud procurasse nelas, se não um substantivo para o espírito estreitamente positivo, pelo menos uma expatriação (dépaysement), como já se revelassem, aqui uma necessidade e uma busca fundamentais. (ASSOUN, 1978, p. 13).
}

Dedicado aos estudos de Medicina, enfrentando cursos pesados como a zoologia pura e a fisiologia, paralelamente, Freud continuava a frequentar os seminários de filosofia de Brentano. No ano de 1875 ele começou a frequentar um curso de lógica aristotélica e, por 
indicação de Brentano, teve contato direto com a filosofia de Stuart Mill e indireto com Platão. Dada a especialização de Brentano, como filósofo aristotélico e psicólogo empirista, Freud teve contato com uma aliança original entre especulação e observação. Essa relação com Brentano oportunizou a Freud aprender a ler filosoficamente. Assoun (1978) define esse momento da vida de Freud como a primeira fala, uma escolha política, marcada por estudos sistemáticos e constantes sobre a Filosofia, a ponto de anos mais tarde, movido pelo desejo de aprendizagem da racionalidade filosófica, pensou em redigir um A. B. C. filosófico, com o intuito de iniciar sua noiva, Martha Bernays, na especulação; “[...] paralelamente a uma carreira médica em vias de decisão, Freud preservara este zelo de leitor filosófico que havia manifestado enquanto era estudante" (ASSOUN, 1978, p. 15). A especulação filosófica será para Freud, enquanto ainda não possuía a especificidade do seu próprio objeto, a tradução de uma busca de um instrumento conceitual de base. A filosofia, de certo modo, será um dos meios a conduzi-lo ao processo de elucidação dos seus próprios conceitos. Aqui, tornando-se eloquente a razão política dessa primeira fala: a filosofia como instrumento para formalização de seu pensamento.

Em determinado momento de sua vida, Freud parece ter-se afastado corajosamente da especulação filosófica, a ponto de a Filosofia parecer-lhe completamente estranha, como se tivesse perdido todas as suas lembranças. É o momento da segunda fala de Freud, escolha política diversa da primeira, mostrando-se alheio às questões filosóficas. "Desta vez, apresenta-se como um estranho aos temas filosóficos. O antigo desejo parece rompido e o antigo investimento retratado" (ASSOUN, 1978, p. 17). Freud passa a evitar qualquer tipo de aproximação da filosofia em sua pesquisa. Fato dito em algumas de suas obras, como em sua autobiografia, Selbsdarstellung. Temos a segunda fala como uma escolha política para afastar o sistema psicanalítico da especulação da filosofia.

Essas duas falas da vida de Freud mostram uma perspectiva interessante que pode ser observada em suas obras. Um pensamento alheio à especulação filosófica, por muitas vezes crítico dos filósofos, convivendo com uma abertura, de certo modo, à mesma especulação filosófica para fundamentar seus conceitos.

Descobrimos aí, com efeito, um discurso ondulante, múltiplo e, finalmente ambivalente: de um lado Freud não possui fórmulas bastante incisivas para desautorizar a filosofia de suas pretensões de legisferar sobre a ciência psicanalítica; do outro, reconhece humildemente sua importância na 'atividade de pensamento' humano. Por um lado, lança aos filósofos sarcasmos que se aproximam da caricatura e do lugar-comum; por outro, constata-se o retorno constante de referências a certos 
sistemas que parecem desempenhar uma função necessária na argumentação freudiana, em seus pontos decisivos. (ASSOUN, 1978, p. 10).

$\mathrm{Na}$ perspectiva dos dois discursos de Freud torna-se possível dizer de um Freud antifilósofo ferrenho ou um Freud filósofo secreto. Fato é que, o ponto de distância entre filosofia e psicanálise é o inconsciente. A descoberta do inconsciente cria toda uma defasagem entre esses dois campos do saber, na fala de Assoun (1978), criando um diálogo de surdos. O objeto da psicanálise, o inconsciente, que Freud empreendeu a tarefa de compreender, era algo oculto para os filósofos. A terceira ferida narcísica atingiu sobremaneira a filosofia.

Esse distanciamento da filosofia, como um ato político (calculado) de Freud, foi importante para a definição da psicanálise como uma ciência da natureza, como qualquer outra - física e química por exemplo. "Isto significa do modo mais claro possível que foi a conquista do seu objeto - o inconsciente - que possibilitou à psicanálise reivindicar-se como Naturwissenschaft (ciência)" (ASSOUN, 1978, p. 58). Freud entendia que o objeto da psicanálise está na ordem do incognoscível, como as outras ciências químicas e físicas, mas que pode ser reduzido ao cognoscível quando estabelecemos leis que submetem esse objeto, podendo ser detectadas as relações recíprocas e suas interdependências, permitindo um conhecimento efetivo, tal como as ciências naturais. A distância política de Freud possibilitou posicionar a psicanálise fora da especulação, em contraposição ao consciencialismo e a Weltanschauung (visão de mundo) filosófica. A visão de mundo da filosofia e a valorização da consciência são tidos como pensamento especular, o que não servia para a constituição da psicanálise como ciência.

\footnotetext{
A concepção totalizante do mundo consiste, para o sujeito cognoscente, em 'tomar por um império num império', no sentido spinozista. É uma ilusão exatamente homóloga que atua na crença no primado absoluto da consciência. Portanto, é por um único e mesmo movimento que a psicanálise refuta o consciencialismo, recusa a filosofia e reivindica-se como ciência. (ASSOUN, 1978, p. 59).
}

Explicitada a posição política de Freud nas duas falas, citadas acima, tomando a importância desse posicionamento para elevar a psicanálise à categoria de ciência, optamos por considerar, portanto, que o inconsciente foi dito de forma indireta por alguns filósofos, destacando Nietzsche, que explicitaremos agora neste artigo, aprofundando sobre a relação entre este filósofo e Freud. 


\section{REFERÊNCIAS DE FREUD A NIETZSCHE}

Freud afirmou ter evitado ler Nietzsche para que não sofresse influências externas na formulação de suas teorias, embora confesse sua admiração pelo filósofo, cujas intuições muitas vezes são confirmadas pelos laboriosos resultados da psicanálise (FREUD, 2012a, p. 247). Apesar disso, encontramos, ao longo da obra de Freud, referências diretas ou indiretas ao filósofo. Este é o caso de um trecho de seu Caso Schreber (1913/2010), onde encontramos uma menção ao hino Antes do nascer do sol, presente em Assim falou Zaratustra. Nesse trecho, Freud escreve que o hino o lembrava de uma situação de uma paciente sua - a qual havia perdido o pai na infância - que situava o pai em tudo o que era grandioso e sublime na natureza, sentimento que ele parecia perceber também no poema do filósofo. Em uma nota de rodapé, ele chama a atenção para o fato de Nietzsche também ter convivido com o pai apenas em sua infância.

Em uma nota do livro Psicopatologia da vida cotidiana (FREUD apud ASSOUN, 1986, p. 61), encontramos mais uma das poucas referências que Freud faz a Nietzsche diretamente, citando o seguinte aforismo 68 de Além do bem e do mal (1992): “'Eu fiz isso’, diz minha memória. 'Eu não posso ter feito isso', diz meu orgulho, e permanece inflexível. Por fim, a memória cede". Ao fazer referência a esse aforismo, Freud demonstra que algumas ideias da psicanálise (nesse caso, a repressão) já haviam sido antecipadas por outros filósofos e pensadores. Para Nietzsche, por exemplo, o esquecimento deve ser uma força ativa - não passiva ou inerte como se poderia crer - funcionando como um "zelador da ordem psíquica"; sem o esquecimento, a pessoa seria um "dispéptico - de nada consegue dar conta" (NIETZSCHE, 1998, p. 48).

No artigo Alguns tipos de caráter encontrados nas práticas psicanalíticas (1914/2010), ao final da seção "Criminosos por sentimento de culpa", Freud relata que um amigo houvera lhe chamado a atenção para o fato de que o criminoso por sentimento de culpa já era do conhecimento de Nietzsche: "No discurso de Zaratustra 'Sobre o pálido criminoso', vislumbramos a preexistência do sentimento de culpa e o recurso ao ato para sua racionalização" (FREUD, 2010, p. 284).

Encontramos outra referência a Nietzsche no capítulo $\mathrm{X}$ do texto Psicologia das massas e análise do eu (1921/2011), quando Freud faz uma surpreendente comparação entre o pai da horda primeva e o super-homem nietzschiano: "no princípio da história humana, ele era o super-homem, que Nietzsche aguardava apenas para o futuro" (FREUD, 2011, p. 86). 
Poderíamos nos questionar se é possível perceber outra referência feita a Nietzsche, ainda que de forma velada, quando Freud utiliza-se do pronome alemão es para designar a parte inconsciente do aparelho psíquico (comumente traduzido no Brasil como id). De acordo com Paulo César de Souza, em uma nota de sua tradução de Além do bem e do mal (1886/1992), é a mesma palavra (que corresponde ao it, no inglês) utilizada por Nietzsche no aforismo 17 da referida obra, para expressar justamente aquilo que é impessoal e necessário no ser humano. $\mathrm{O}$ aforismo afirma que não necessariamente é um "eu" que pensa por sua própria vontade, mas um pensamento pode vir independente de sua vontade (isso pensa) (NIETZSCHE, 1992, p. 226-228).

\section{O INCONSCIENTE EM FREUD E NIETZSCHE: CARACTERÍSTICAS GERAIS}

A partir das referências acima citadas, a questão que se coloca é: até que ponto podese considerar o inconsciente freudiano influenciado pelo de Nietzsche?

Em O mal estar na civilização (1929/2011), Freud declara que os instintos humanos são essencialmente busca pelo prazer (sexual e na alimentação) e agressão exteriorizada. A gênese do inconsciente se daria a partir do momento em que, para constituir uma comunidade, o homem tenha de abdicar, em dadas situações, tanto de sua busca pelo prazer sexual quanto de seu pendor para a agressividade. Assim, tudo o que não é admissível para a sociedade é reprimido, mandado para o inconsciente. Em Totem e tabu (1913/2013) inconsciente é tudo o que a consciência não admite, porém permanece como desejo inconsciente. A relação da consciência com esse desejo é sempre ambivalente. Desse modo, o instinto seria o supremo egoísmo, e para a construção de uma comunidade, em que deve prevalecer o espírito de cooperação, tudo o que prejudica essa comunidade deve ser reprimido ou sublimado. $\mathrm{Na}$ sublimação, o instinto se desvia de seu objetivo inicial para outro, menos satisfatório, porém de forma que ele possa ser realizado. Freud cita exemplos de impulsos sublimados: amizade (instinto sexual "inibido na meta"), a arte, o trabalho. A sublimação está presente em todos nós, e "a psicanálise mostrou que a repressão e outros processos psicológicos não estão de maneira alguma restritos aos neuróticos" (KAUFMANN, 1980, p. 331). O sonho mesmo é um exemplo de material inconsciente reprimido, momentaneamente presente no consciente.

Se, para Freud, o livre arbítrio é apenas um mito fabricado pelo narcisismo humano e demonstrado como falso pela psicanálise, pensa Nietzsche de forma semelhante, como pode ser verificado no aforismo 21 de Além do bem e do mal (1886/1992). Para ele, o livre arbítrio 
seria algo criado pelo homem, um "preconceito", para que pudesse julgar os homens, com tranquilidade, por todos os seus atos. Se cada ação tem a permissão da consciência, então pode-se julgar o homem por elas, e ele é responsável por cada uma delas. Segundo Nietzsche isso é falso, pois nossas ações muitas vezes têm outras fontes, além da consciência:

\begin{abstract}
A total irresponsabilidade do homem por seus atos e seu ser é a gota mais amarga que o homem do conhecimento tem de engolir, se estava habituado a ver na responsabilidade e no dever a carta de nobreza de sua humanidade. Todas as suas avaliações, distinções, aversões, são assim desvalorizadas e se tornam falsas: [...]; ele já não pode louvar nem censurar, pois é absurdo louvar e censurar a natureza e a necessidade. (NIETZSCHE, 2000, p. 81).
\end{abstract}

Porém, Nietzsche não se contenta com um "cativo-arbítrio": "O cativo-arbítrio não passa de mitologia: na vida real existem apenas vontades fortes e fracas" (NIETZSCHE, 1992, p. 27). Consequentemente, ele não aceitaria a tese de que a consciência estaria completamente subordinada aos impulsos e instintos inconscientes, criando uma oposição:

\begin{abstract}
A maior parte do pensamento consciente deve ser incluída entre as atividades instintivas [...]. Assim como o ato de nascer não consta no processo e no progresso geral da hereditariedade, também "estar consciente" não se opõe de algum modo decisivo ao que é instintivo - em sua parte, um pensamento de um filósofo é secretamente guiado e colocado em certas trilhas pelos seus instintos. (NIETZSCHE, 1992, p. 11).
\end{abstract}

Para Santos (2011), o inconsciente em Nietzsche difere precisamente daquele de Freud por não estabelecer uma relação de opressão com o consciente. $\mathrm{O}$ inconsciente e seus instintos seriam tão necessários para uma vida saudável (sem qualquer censura, repressão ou sublimação), quanto o consciente, o que não se dá em Freud. Encontramos uma percepção semelhante em Naffah Neto (1997), que, após ressaltar que ambos os autores pensam o inconsciente como desprovido de linguagem, diz:

Entretanto, enquanto Nietzsche empurra o inconsciente para a vertente da experiência inusitada, rara, indizível e irrepresentável pela vulgaridade do verbo, Freud tende a pensá-la na vertente do proibido: é moralmente condenada, capaz de gerar uma angústia suficiente para expulsar da consciência a sua representação. (NAFFAH NETO, 1997, p. 48).

De modo geral, é possível perceber que Freud compreendeu o inconsciente como dimensão desconhecida no ser humano, tão determinante ou mais para nossas ações quanto o consciente, e que ele reconhece concepção semelhante em Nietzsche. Entretanto, para Freud, o inconsciente se compõe essencialmente de elementos incompatíveis com os valores de uma 
cultura e sociedade, que foram reprimidos também sem o conhecimento do Eu (a consciência). Em sua obra, o inconsciente é determinado por valores ou proibições, não somente por lembranças e experiências que não possuem representação na linguagem, sendo este, aparentemente, o ponto de vista nietzschiano.

\section{O INCONSCIENTE SUBVERSIVO EM FREUD E O ALÉM-DO-HOMEM NIETZSCHIANO}

A introdução do conceito de inconsciente por Freud marca uma ruptura com a maneira moderna de se pensar psicologia. Antes dele, seria absurdo para qualquer psicólogo se alguém propusesse algum fenômeno psíquico que não fosse também consciente. $\mathrm{O} 3^{\circ}$ golpe infligido ao narcisismo do homem, assim Freud o descreve, propõe que não somos tão livres como sempre foi pensado, e o ego não é senão uma pequena parte da estrutura psíquica humana (FREUD, 2014, p. 310-311).

A era moderna, iniciada por René Descartes, tem como seu critério de verdade a consciência. Sua afirmativa "penso, logo, existo" marca uma ruptura com a epistemologia da era clássica. Uma das consequências desse novo modo de pensar é a instauração da dúvida quanto aos dados empíricos, antes considerados como absolutos. As sensações passam a não ser mais um critério válido de verdade: o antropocentrismo seria apenas um dos infinitos erros aos quais os sentidos podem nos induzir. A instauração da dúvida nos permite questionar a verdade, a existência de tudo, mas essa mesma dúvida já é em si uma forma de pensamento. $\mathrm{O}$ que nos leva a afirmar: se duvido, existo.

Portanto, é possível pensar o giro no pensamento operado por Descartes como revolucionário - de um lado, porque se volta contra um saber anterior estabelecido e, de outro, pois é referenciado pela perspectiva de construção de um saber totalizante.

Já a noção de inconsciente proposta por Freud é subversiva porque substitui a discussão de um ideal totalizante para a cena de um desejo singularizante. Ela se impõe por ser necessária à compreensão de processos psíquicos na clínica e que podem ser observados cotidianamente nos atos falhos, parapraxias, os quais a psicologia da consciência se revelara insuficiente para sua inteligibilidade. É importante ressaltar que a subversão operada pelo inconsciente freudiano é justamente no sujeito cartesiano, que é, paradoxalmente, o ponto de partida da psicanálise. 
Podemos pensar, aqui, em diversos artistas e filósofos que, a partir de uma intuição, chegaram a antecipar conceitos psicanalíticos, o inconsciente entre eles. Como discutido acima, o inconsciente proposto por Friedrich Nietzsche não seria menos subversivo que o psicanalítico, embora a aversão do filósofo por sistemas científicos e filosóficos o tenha impedido de defini-lo com precisão.

Para compreender o inconsciente de Nietzsche, é fundamental um aprofundamento da noção de Super-homem. Em seu livro Assim falou Zaratustra (1885/2011), encontramos, na seção intitulada "Os três discursos", ainda que em uma linguagem altamente simbólica e metafórica reminiscente de textos sagrados como o Antigo Testamento, uma descrição dos caminhos que o homem deve tomar até atingir o Super-homem ${ }^{1}$.

Nessa obra, nos deparamos com uma concepção de ser humano como uma coisa excessivamente incompleta. É uma corda sobre o abismo, estendida entre o animal e o Alémdo-homem (Super-homem). Espera-se uma passagem para esse estágio de superioridade, deixando a incompletude do homem para alcançar o Além-do-homem. Trazemos, aqui, a ideia de superação. O Além-do-homem é a superação de todo ressentimento, é a criança que está por vir. Criança que é o terceiro estágio da Metamorfose do espírito.

Antes de falarmos das três metamorfoses do espírito, convém destacar que espírito é esse de que Nietzsche fala. O espírito nietzschiano contrapõe ao Espírito Absoluto de Hegel, com isso vai contra a fenomenologia do espírito hegeliana. Esta Fenomenologia vê o Espírito Absoluto como a coroação de todas as coisas, presente em todas as etapas de seu processo de constituição. O espírito na obra de Nietzsche é uma força inclinada à destruição, para recomeçar do zero, que gera uma nova criação. É o espírito de artista, que molda, que cria, uma subversão. Nietzsche, na obra Assim falou Zaratustra, fala das três metamorfoses, do espírito ao camelo, do camelo ao leão e da transformação do leão em criança.

O camelo é símbolo da aceitação, da besta de carga que se ajoelha para receber todo o peso. Aceitação que tende para a submissão, rebaixamento, humilhação, humildade. É aceitar que esse modo do espírito faz brilhar a tolice. Por mais que se dedique muito esforço e empenho, isso nada mais é que uma simples sujeição e obediência do espírito. "Todas essas

\footnotetext{
'A palavra Übermensch é normalmente traduzida de duas maneiras: "Super-homem" e "Além-do-homem". Podem ser entendidas como sinônimos, pelo significado que cada uma traz. Ambas apresentam a ideia de superação. Optaremos, por questões metodológicas, pela tradução Além-do-homem, pois a compreensão atual de Super-homem evoca a ideia de poder, de força, de um homem poderoso e Nietzsche, com esse conceito, dizia que o homem é algo a ser superado, é preciso criar algo que ultrapassa, em certo sentido podemos dizer de evolução. Do verme para o homem e do homem para o Além-do-homem.
} 
coisas mais que pesadas o espírito resistente toma sobre si. Semelhante ao camelo que ruma carregado para o deserto, assim ruma ele para o seu deserto.” (NIETZSCHE, 2011, p. 28) O deserto é o lugar da extrema solidão, lugar onde acontece a segunda metamorfose. O camelo se transforma em leão, que quer conquistar a liberdade. Em vez de aceitar o imperativo "Tu deves", que remete à observância aos valores aos quais o camelo teria pressa em ajoelhar, o espírito do leão quer dizer "Eu quero", no sentido de criar seus próprios valores, criar liberdade para si. "Criar valores novos - mesmo o leão não é capaz disso; mas criar para si a liberdade de novas criações - isso a força do leão pode fazer." (NIETZSCHE, 2011, p. 32) O leão é o camelo que apercebe sua força, que descobre suas capacidades e tem coragem de dizer não frente ao dever, em vez de renunciar. É preciso ser o leão para dizer não, para criar seus próprios valores, porém essa é a mais terrível empreitada para um espírito resignado e respeitoso. Abrindo, então, perspectivas para uma liberdade criadora, chega o momento derradeiro da transformação do espirito: o leão deve tornar-se criança. "A criança é inocência e esquecimento, um novo começo, um jogo, uma roda que gira por si mesma, um primeiro movimento, um sagrado Sim.” (NIETZSCHE, 2011, p. 28) A criança é a imagem da abertura, das possibilidades, de liberdade. É preciso ser criança para brincar o brinquedo dos criadores. A criança tem o que o camelo e o leão não têm: a capacidade de jogar, brincar, criar, girar sobre si mesma. Para Nietzsche esse último estágio coincide como o Além-do-homem.

A dinâmica da vida passa pelos momentos em que os discursos são ora os do leão destruidor e ora os da criança criadora. Um caminho dialético, uma subversão, que em Nietzsche é passiva. A criança é capaz de colocar no mundo o que está no seu íntimo. O empenho da criança não é carregar os valores (camelo), nem destruí-los (leão), é o devir, uma independência voltada para a criação.

As três metamorfoses são uma forma de expressarmos a liberdade. O camelo sente-se livre, mas o é enquanto sente-se confortável em seguir as normas, respeitar os valores. É resistente, a ponto de carregar pesados fardos, com a sensação de ser isso a liberdade. $\mathrm{O}$ espírito do camelo tem a esperança de que sofrendo as agruras da vida nesse mundo, receberá uma grande recompensa no outro mundo. O leão é livre ao dizer não às regras, ao se opor às normas e valores. Ele quer ser livre de valores que não são seus, um sentimento de recusa àquilo que não lhe pertence nem convém. A liberdade aqui coincide com a destruição. É a subversão reativa, que rompe com os valores antigos, para criar valores novos para si. A criança, por sua vez, expressa a liberdade criadora, que parte do zero para criar novos valores. Diferente do leão que tem sua autonomia ainda presa nos valores antigos, é a liberdade que 
mostra do contra àquilo que não lhe agrada. A criança é a abertura para a criatividade criadora. Ela cria para si mesma o seu próprio bem e mal, tornando-se seu próprio juiz. A conservação e a destruição não são importantes nesse estágio, aqui é o lugar da criação sempre nova. Nietzsche fala que os deuses estão todos mortos, então cabe à criança a responsabilidade da nova criação, de criar um mundo novo.

A criança é o inconsciente sem qualquer repressão. A vida do Além-do-homem, a "vida do artista", na expressão do filósofo, seria uma vida que abolisse as determinações e a visão moral de mundo, um além do bem e do mal, além das antíteses hegelianas, além da linguagem. Retomando o que foi dito acima acerca da referência feita por Freud ao pai da horda primeva como sendo o Além-do-homem, é importante notar que essa referência marca um ponto em comum do que ambos os autores entendem por Além-do-homem: o indivíduo sobre o qual não incide qualquer espécie de repressão. Entretanto, Freud o situa no começo da humanidade, e Nietzsche, no futuro. Freud dirá que esse pai goza de uma liberdade excepcional e tem uma natureza "absolutamente narcisista" (FREUD, 2011, p. 86), não precisa amar mais ninguém. Justamente por isso, não é capaz de criar laços e fundamentar uma cultura. O Super-homem nietzschiano, por outro lado, situa-se no futuro, precisa passar pelas "três metamorfoses", pela cultura, para poder finalmente conhecer essa liberdade excepcional.

É possível, ainda, fazermos uma analogia das três metamorfoses com as instâncias psíquicas propostas por Freud em sua segunda tópica: O Superego corresponderia ao camelo (representado pelo "tu deves”), o Ego, ao leão (“eu quero”) e a criança ao Id, puro ato criativo, indeterminação, fora da linguagem. Ainda que tenha seus limites por ser meramente descritiva, essa metáfora oferece uma melhor compreensão do que seria cada momento das metamorfoses descritas por Nietzsche.

\section{CONSIDERAÇÕES FINAIS}

O objetivo deste trabalho foi, em um primeiro momento, destacar a ambivalente relação de Freud com a filosofia. Vimos como esta pode ser dividida em duas "falas": uma primeira, marcada pelo interesse e busca de aprofundamento do saber filosófico, a exemplo de sua relação com Brentano; e uma segunda, em uma postura de afastamento que chega ao desdém. Ambas não são excludentes e podem ser verificadas convivendo ao mesmo tempo. 
Tomamos como exemplo privilegiado para este artigo o diálogo que Freud estabelece com Nietzsche e, mais especificamente, o que no conceito psicanalítico de inconsciente pode ser considerado como devedor da concepção nietzschiana e em quais aspectos os autores divergem. Apesar de Freud declarar não conhecer a obra do filósofo e ter evitado propositalmente sua leitura, várias referências a ele são feitas, direta ou indiretamente, em seus próprios textos.

Foi possível concluir, entretanto, que, se Freud tem em comum com Nietzsche o inconsciente como determinante para as ações humanas (destituindo definitivamente a consciência como único domínio psíquico possível e relegando-a a uma posição secundária), e como desprovido de linguagem, Nietzsche recusa a concepção de uma consciência em relação de oposição com o inconsciente. Essa recusa se insere na busca que Nietzsche propõe pela superação das oposições, das antíteses (bom-mau, moral-imoral, conscienteinconsciente) e que culminaria no estágio superior da humanidade, o Super-homem. Para ele, o inconsciente não deve absolutamente ser reprimido. Perspectiva esta, completamente incompatível com a psicanálise, já que, como vimos, o Super-homem, de acordo com Freud, se assemelharia mais ao pai da horda primeva, absolutamente livre em seu narcisismo, incapaz de amar e de fundar uma cultura sobre laços sociais.

\section{REFERÊNCIAS}

ASSOUN, P. Freud y Nietzsche. México: Fondo de cultura económica, 1986.

ASSOUN, P. Freud: a filosofia e os filósofos. Rio de Janeiro: Francisco Alves, 1978.

FREUD, S. Algumas considerações sobre o conceito de inconsciente na psicanálise. In:

Obras completas. Vol. 10. São Paulo: Companhia das Letras, 2010a, p. 255-268.

FREUD, S. A história do movimento psicanalítico. In: Obras completas. Vol. 11. São Paulo: Companhia das Letras, 2012a, p. 245-327.

FREUD, S. Alguns tipos de caráter encontrados nas práticas psicanalíticas. In: Obras completas. Vol. 12. São Paulo: Companhia das Letras, 2010b, p. 253-284.

FREUD, S. Ensaios de metapsicologia - O inconsciente. In: Obras completas. Vol. 12. São Paulo: Companhia das Letras, 2010c, p. 99-150.

FREUD, S. Totem e tabu. São Paulo: Penguin, 2013.

FREUD, S. Conferências introdutórias à psicanálise. In: Obras completas. Vol. 13. São Paulo: Companhia das Letras, 2014. 
FREUD, S. Psicologia das massas e análise do eu. In: Obras completas. Vol. 15. São Paulo: Companhia das Letras, 2012b, p. 13-99.

FREUD, S. O mal-estar na civilização. São Paulo: Penguin, 2011.

HÉBER-SUFFRIN, Pierre. O Zaratustra de Nietzsche. Tradução Lucy Magalhães. Rio de Janeiro: Erudição e Prazer, 1994.

KAUFMANN, W. From Shakespeare to existentialism. Princeton: Princeton University Press, 1980.

MOREIRA, J. O. O inconsciente e a política: entre a estrangeiridade e a extimidade. No prelo.

NAFFAH NETO, A. Nietzsche e a psicanálise. Cadernos Nietzsche, v. 2, p. 41-53, 1997.

NIETZSCHE, F. Humano, demasiado humano. São Paulo: Companhia das Letras, 2000.

NIETZSCHE, F. Além do bem e do mal. São Paulo: Companhia das Letras, 1992.

NIETZSCHE, F. Assim falou Zaratustra. São Paulo: Companhia das Letras, 2011.

NIETZSCHE, F.Genealogia da moral. São Paulo: Companhia das Letras, 1998.

SANTOS, M. F. O homem que foi um campo de batalha. In: NIETZSCHE, F: Vontade de Potência. Petrópolis: Vozes, 2011, p. 15-120. 